\title{
Emerging trends in non-communicable disease mortality in South Africa, 1997 - 2010
}

\author{
B Nojilana, ${ }^{1} \mathrm{MPH} ;$ D Bradshaw, ${ }^{1}$ DPhil, MSc; V Pillay-van Wyk, ${ }^{1} \mathrm{PhD}$ (Paediatrics), MPH (Epidemiology and Biostatistics); \\ W Msemburi, ${ }^{1}$ MPhil (Demography), BSc Hons (Statistics); R Laubscher, ${ }^{2}$ BCom (Maths); N I M Somdyala, ${ }^{1}$ MDS, BCur; \\ J D Joubert, ${ }^{1} \mathrm{PhD}$, MA (Socio-linguistics); MA (Demography); P Groenewald, ${ }^{1} \mathrm{MB}$ ChB, MPH; R E Dorrington, ${ }^{3}$ MPhil (FASSA), \\ BCom, BA, BSc Hons; on behalf of the South African National Burden of Disease team
}

\author{
${ }^{1}$ Burden of Disease Research Unit, South African Medical Research Council, Cape Town, South Africa \\ ${ }^{2}$ Biostatistics Unit, South African Medical Research Council, Cape Town, South Africa \\ ${ }^{3}$ Centre for Actuarial Research, Faculty of Commerce, University of Cape Town, South Africa
}

Corresponding author: B Nojilana (beatrice.nojilana@mrc.ac.za)

Objectives. National trends in age-standardised death rates (ASDRs) for non-communicable diseases (NCDs) in South Africa (SA) were identified between 1997 and 2010.

Methods. As part of the second National Burden of Disease Study, vital registration data were used after validity checks, proportional redistribution of missing age, sex and population group, demographic adjustments for registration incompleteness, and identification of misclassified AIDS deaths. Garbage codes were redistributed proportionally to specified codes by age, sex and population group. ASDRs were calculated using mid-year population estimates and the World Health Organization world standard.

Results. Of 594071 deaths in 2010, 38.9\% were due to NCDs (42.6\% females). ASDRs were 287/100 000 for cardiovascular diseases (CVDs), 114/100 000 for cancers (malignant neoplasms), 58/100 000 for chronic respiratory conditions and 52/100 000 for diabetes mellitus. An overall annual decrease of $0.4 \%$ was observed resulting from declines in stroke, ischaemic heart disease, oesophageal and lung cancer, asthma and chronic respiratory disease, while increases were observed for diabetes mellitus, renal disease, endocrine and nutritional disorders, and breast and prostate cancers. Stroke was the leading NCD cause of death, accounting for 17.5\% of total NCD deaths. Compared with those for whites, NCD mortality rates for other population groups were higher at 1.3 for black Africans, 1.4 for Indians and 1.4 for coloureds, but varied by condition.

Conclusions. NCDs contribute to premature mortality in SA, threatening socioeconomic development. While NCD mortality rates have decreased slightly, it is necessary to strengthen prevention and healthcare provision and monitor emerging trends in cause-specific mortality to inform these strategies if the target of $2 \%$ annual decline is to be achieved.

S Afr Med J 2016;106(5):477-484. DOI:10.7196/SAMJ.2016.v106i5.10674

Non-communicable diseases (NCDs) have been recognised as a major cause of disability and death ${ }^{[1-5]}$ for three decades. The 2010 Global Burden of Disease Study ${ }^{[1]}$ estimated that NCD deaths increased from about 8 million in 1990 to 52.8 million in 2010, or $65 \%$ of all deaths in that year. A high proportion of the burden occurs in lowand middle-income countries ${ }^{[1-7]}$ In 2005, Strong et al. ${ }^{[8]}$ suggested a target of reducing chronic disease mortality by $2 \%$ per annum, and the high-level United Nations summit on NCDs in September 2011 heralded a global commitment to address the growing burden. ${ }^{[9,10]}$ Countries agreed to adopt nine global targets, ${ }^{[11]}$ including the ' $25 \times 25$ ' overarching target of reducing premature mortality from the four main NCDs (cardiovascular diseases (CVDs, including cerebrovascular disease), chronic respiratory diseases, cancers and diabetes mellitus) by $25 \%$ compared with their 2010 levels by 2025 .

The decline in NCD mortality rates observed in most highincome countries since the $1960 \mathrm{~s}^{[12-14]}$ has been attributed to decreases in population levels of major risk factors including smoking, unhealthy diet, physical inactivity and alcohol use, ${ }^{[3,13,15,16]}$ as well as improved treatment. ${ }^{[12,15]}$ There are limited data on trends in mortality rates in low- and middle-income countries, ${ }^{[10]}$ although it is predicted that NCDs will continue to rise in these countries owing to population ageing and lifestyle changes associated with socioeconomic development and urbanisation. ${ }^{[3,12,16-18]}$

The initial South African (SA) National Burden of Disease Study estimated that in 2000 NCDs accounted for $41 \%$ of all deaths. ${ }^{[19]}$
SA has relatively high levels of risk factors for NCDs. ${ }^{[20]}$ With the exception of reductions in tobacco smoking from $34 \%$ in $1995,{ }^{[21]}$ prior to the anti-tobacco legislation, to $24 \%$ in 2009 , other NCD risk factors have increased with distinct gender patterns. In 2008, $43 \%$ of men and $41 \%$ of women had raised blood pressure, ${ }^{[22]} 46 \%$ of men and $56 \%$ of women were physically inactive, ${ }^{[22]}$ and the prevalence of overweight and obesity was $58.5 \%$ for men and $71.8 \%$ for women. ${ }^{[22,23]}$ The prevalence of raised blood cholesterol was $31 \%$ for men and $37 \%$ for women, and $5.9 \%$ of men and $2.0 \%$ of women ${ }^{[24]}$ reported risky alcohol use.

The second National Burden of Disease Study for SA is focusing on trends in deaths and premature mortality from 140 causes of death. ${ }^{[25]}$ In this article we report on deaths from NCDs and examine trends in age-standardised death rates (ASDRs) between 1997 and 2010 nationally and by population group from 2000 onwards.

\section{Methods}

Death data obtained from Statistics South Africa for 1997 - 2010 were used for the analysis of NCD mortality. ${ }^{[26]}$ The analysis steps are detailed elsewhere. ${ }^{[25]}$ Briefly, data integrity was assessed using data cleaning processes and validity, and adjustments were made for underreporting. Causes of death were grouped according to the SA National Burden of Disease list, comprising four broad cause groups: HIV/AIDS and tuberculosis; other communicable diseases, plus maternal, perinatal and nutritional conditions; non-communicable 
diseases; and injuries, with 24 disease categories and 140 single causes. ${ }^{[25]}$ In this article stroke is used interchangeably with cerebrovascular disease, renal disease with nephritis and nephrosis, and cancers with malignant neoplasms.

For selected underlying causes of death (UCODs), the data were recoded to address identified inconsistencies based on epidemiological and clinical expertise within the team. These included the selection of diabetes mellitus or epilepsy as the UCOD for cases based on the multiple-competing UCOD reported in part 1 of the death notification form. ${ }^{[27]}$ Cases with diabetes mellitus as the UCOD that had a competing cause reported in part 1 were recoded to: $(i)$ stroke (I60-I69) if stroke was also reported in part 1; (ii) ischaemic heart disease (IHD) (I20-I25) if this was also reported in part 1; (iii) hypertensive heart disease (I11) if this was also reported in part 1; and (iv) nephritis and nephrosis (N00N08, N10-N12, N17-N19) if hypertensive renal disease (I12) was also reported in part 1. Cases in which epilepsy (G40-G41) was reported as the UCOD with stroke (I60-I69) as the competing cause were recoded to stroke (I60-I69). Cases with hypertension (I10) reported with no other UCOD were redistributed proportionally by age and sex to hypertensive heart disease (I11), hypertensive renal disease (I12), hypertensive renal and heart disease (I13), renal disease (N00-N08, N10-N12, N17-N19), IHD (I20-I25), cerebrovascular disease (I60-I69, G81) and aortic aneurysm (I71), while those with other causes reported were recoded to general ill-defined. Cases with hypertensive renal disease (I12) as the UCOD were combined with other nephritis and nephrosis (N00-N08, N10N12, N17-N19), while hypertensive heart and renal disease (I13) were combined with hypertensive heart disease (I11).

Deaths with unknown age, sex and population group were redistributed proportionally, ${ }^{[25]}$ misclassified HIV/AIDS deaths were identified from 18 conditions (none NCDs) based on a regression approach, and underspecified and illdefined conditions were redistributed according to the strategies developed by the team in consultation with experts. ${ }^{[28]}$ Years of life lost (YLLs) were calculated using $3 \%$ per annum discounting ${ }^{[29]}$ and the level 26 West model life-table ${ }^{[30,31]}$ for standard expectations by age. ASDRs were calculated using alternative midyear estimates ${ }^{[32]}$ and the World Health Organization world standard. ${ }^{[33]}$ Premature mortality from CVDs, cancers, respiratory disease and diabetes mellitus was calculated as the risk of death $\left({ }_{40} \mathrm{q}_{30}\right)$ from these causes between the ages of 30 and 70 years based on the quinquennial death rates $\left({ }_{5} \mathrm{~m}_{\mathrm{x}}\right)$, such that:

$$
{ }_{40} q_{30}=1-\exp \left(-5 \sum_{\left.x=30[5]{ }_{5} m_{x}\right)}^{65}\right.
$$

National trends in deaths and ASDRs are reported by broad cause groups, categories of conditions and single causes. Population group according to previously defined apartheid categories of black African, coloured, Indian/Asian, white and other was introduced into the new death notification in $1998^{[34]}$ to track health inequalities. Since population group was reported for about $75 \%$ of deaths since 2000 , it was possible to estimate trends by population group for $2000-2010$.

\section{Results}

\section{NCD mortality}

Of the estimated 594071 deaths in 2010, $38.9 \%$ were due to NCDs $(42.6 \%$ of females and $35.4 \%$ of males). A sizeable proportion $(14.7 \%)$ of those who died were aged $<45$ years and $21.5 \%$ were aged 45 - 59 years, indicating a considerable number of premature deaths. Premature mortality (30 - 70 years) for CVDs, cancer, respiratory conditions and diabetes mellitus remained level at about $29.0 \%$ until 2004 , but by 2010 had declined to $26.0 \%$.
Based on YLLs, NCDs accounted for $27.8 \%$ of the premature burden $(30.1 \%$ of female YLLs and $25.7 \%$ of male YLLs) in 2010. The ASDR for NCDs was level at about 669/100 000 population from 1997, then increased in 2003 to $710 / 100000$ population before declining again to $634 / 100000$ population in 2010. A drop from $817 / 100000$ population (in 2003) to $747 / 100000$ (2010) for males, and from $631 / 100000$ population to $560 / 100000$ for females, was observed. In addition to the differences by sex, Fig. 1 shows differentials by population group. The ASDRs for white South Africans were substantially lower than other groups. Small declines were observed for black Africans and whites, with more marked declines for Asians and coloureds since 2000.

Despite decreasing rates, Fig. 2 shows the increasing number of deaths from NCDs since 1997, reaching just over 230000 by 2010. The decomposition of the change between 1997 and 2010 (Table 1) indicates that the increase is due to population growth and a change in age structure, particularly for females.

The cause composition of NCD deaths changed very slightly, and by $2010,44.0 \%$ of NCD deaths were due to CVDs, $18.0 \%$ to cancers, $9.3 \%$ to chronic respiratory diseases and $8.0 \%$ to diabetes mellitus. For that year, the leading single cause of NCD deaths was stroke, followed by IHD, hypertensive heart

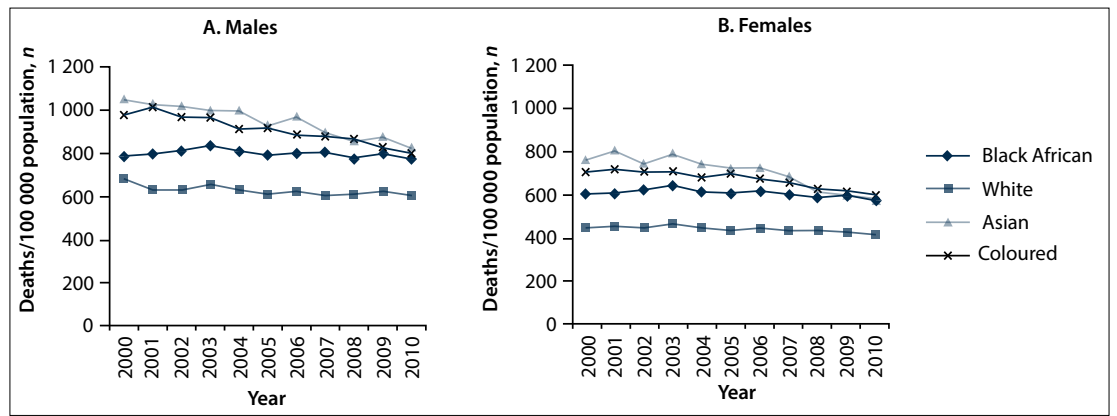

Fig. 1. ASDRs from NCDs for males (A) and females (B) by population group, SA 2000 - 2010.

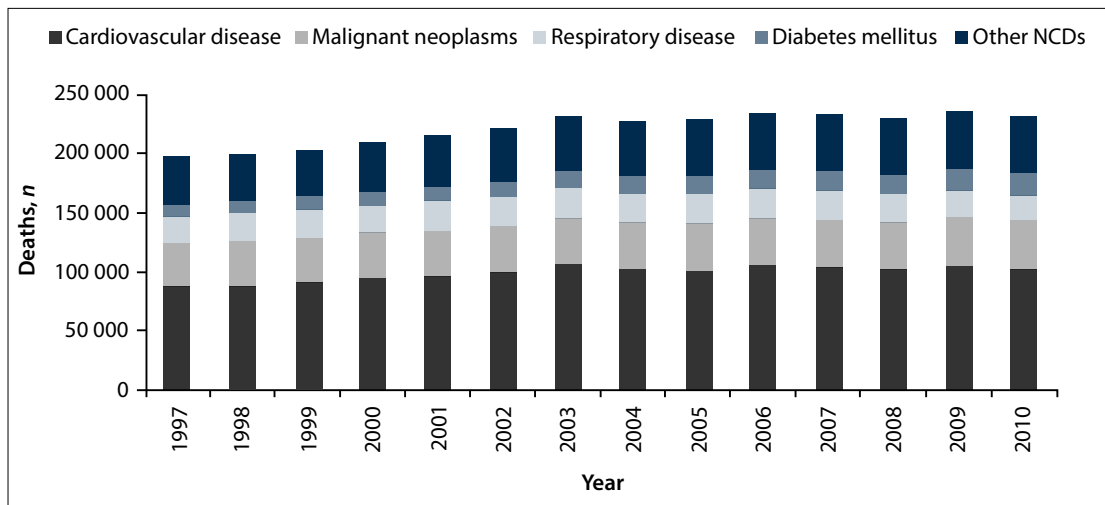

Fig. 2. Number of deaths from NCDs, SA 1997 - 2010. 
disease and diabetes mellitus (Table 2). For females, cervical and breast cancers ranked in the top 10 causes of death, while lung and prostate cancers were reported for males. Substantial increases in ASDRs were observed for diabetes mellitus, renal disease, prostate and breast cancer, and endocrine, nutritional, blood and immune disorders, while decreases occurred for chronic obstructive pulmonary disease (COPD), asthma and lung cancer.
From Table 2 it can also be seen that the overall decline in ASDRs from NCDs was $5 \%$ over the 14 -year period, or $0.4 \%$ per year, much lower than the recommended goal of $2 \%$ per year.

\section{CVDs, diabetes mellitus and renal disease}

Cerebrovascular disease, the leading CVD cause of death, has been the leading cause

Table 1. Decomposition of change in NCDs into population growth, change in rate and change in age

\begin{tabular}{|c|c|c|c|}
\hline & Male & Female & Total \\
\hline 1997 deaths & 99520 & 97318 & 196838 \\
\hline $\begin{array}{l}\text { Deaths expected with } 2010 \text { population, } 1997 \text { population } \\
\text { age structure, } 1997 \text { death rates, } n\end{array}$ & 115616 & 112980 & 228593 \\
\hline $\begin{array}{l}\text { Deaths expected with } 2010 \text { population, } 2010 \text { population } \\
\text { age structure, } 1997 \text { death rates, } n\end{array}$ & 119077 & 128163 & 247240 \\
\hline 2010 deaths & 108405 & 122724 & 231129 \\
\hline Change from 1997 due to population growth, \% & 16.2 & 16.1 & 16.1 \\
\hline Change from 1997 due to change in age structure, \% & 3.5 & 15.6 & 9.5 \\
\hline Change from 1997 due to change in death rates, \% & -10.7 & -5.6 & -8.2 \\
\hline Change from 1997 to $2010, \%$ & 8.9 & 26.1 & 17.4 \\
\hline
\end{tabular}

of NCD deaths over the period. In 2010 it became the second leading cause of total deaths following HIV/AIDS (accounting for $5.1 \%$ of total male deaths and $8.6 \%$ of total female deaths). Stroke mortality rates were similar for males and females and increased to about $133 / 100000$, followed by a decline to about $114 / 100000$ in 2010 (Fig. 3). In contrast, IHD mortality rates declined slightly and male rates were about 1.8 times higher than rates for females in 2010. Hypertensive heart disease and cardiomyopathy showed little change over the period. While hypertensive heart disease was slightly higher for females than males, death rates from cardiomyopathy were 1.3 times higher for males. Death rates from diabetes mellitus and renal disease increased steadily. While death rates for diabetes mellitus were similar for males and females, renal disease death rates were higher for males than females.

ASDRs for CVDs and diabetes mellitus by gender and population group for the years 2000 - 2010 are shown in Fig. 4. Marked declines in CVDs and diabetes mellitus were noted among coloureds and Asians, while there was an increase among black Africans.

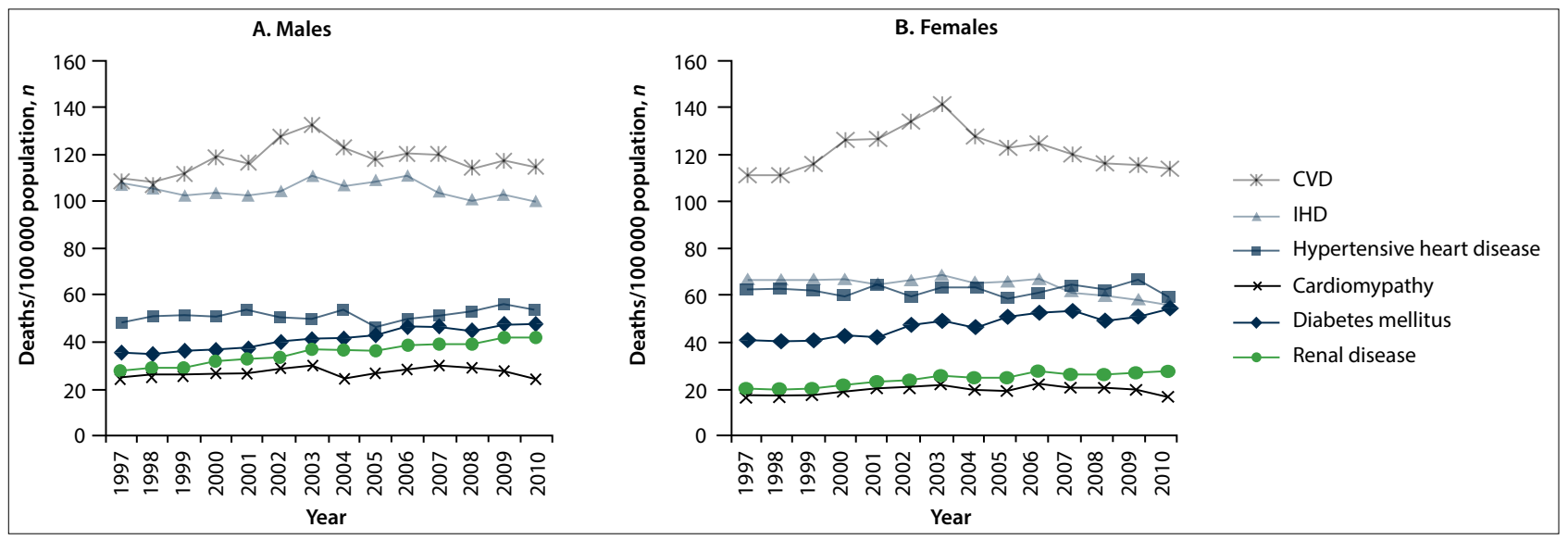

Fig. 3. ASDRs for CVDs, diabetes mellitus and renal disease for males (A) and females (B), SA 1997 - 2010.

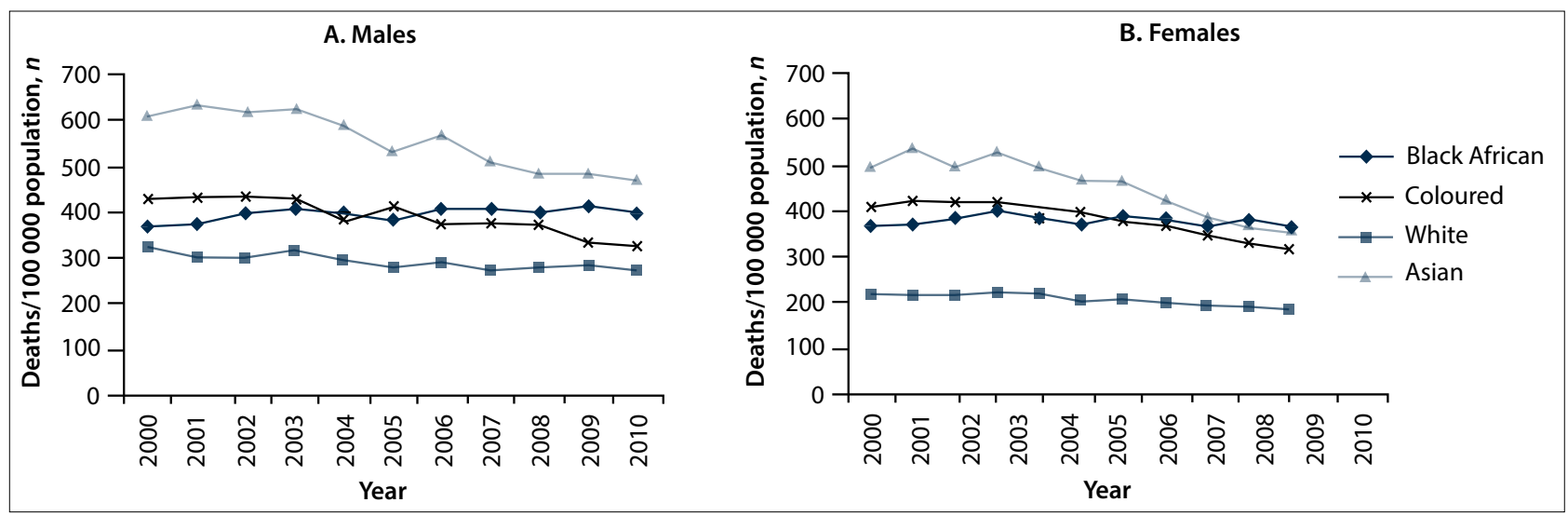

Fig. 4. ASDRs for CVDs and diabetes mellitus for males (A) and females (B) and population group, SA 2000 - 2010. 


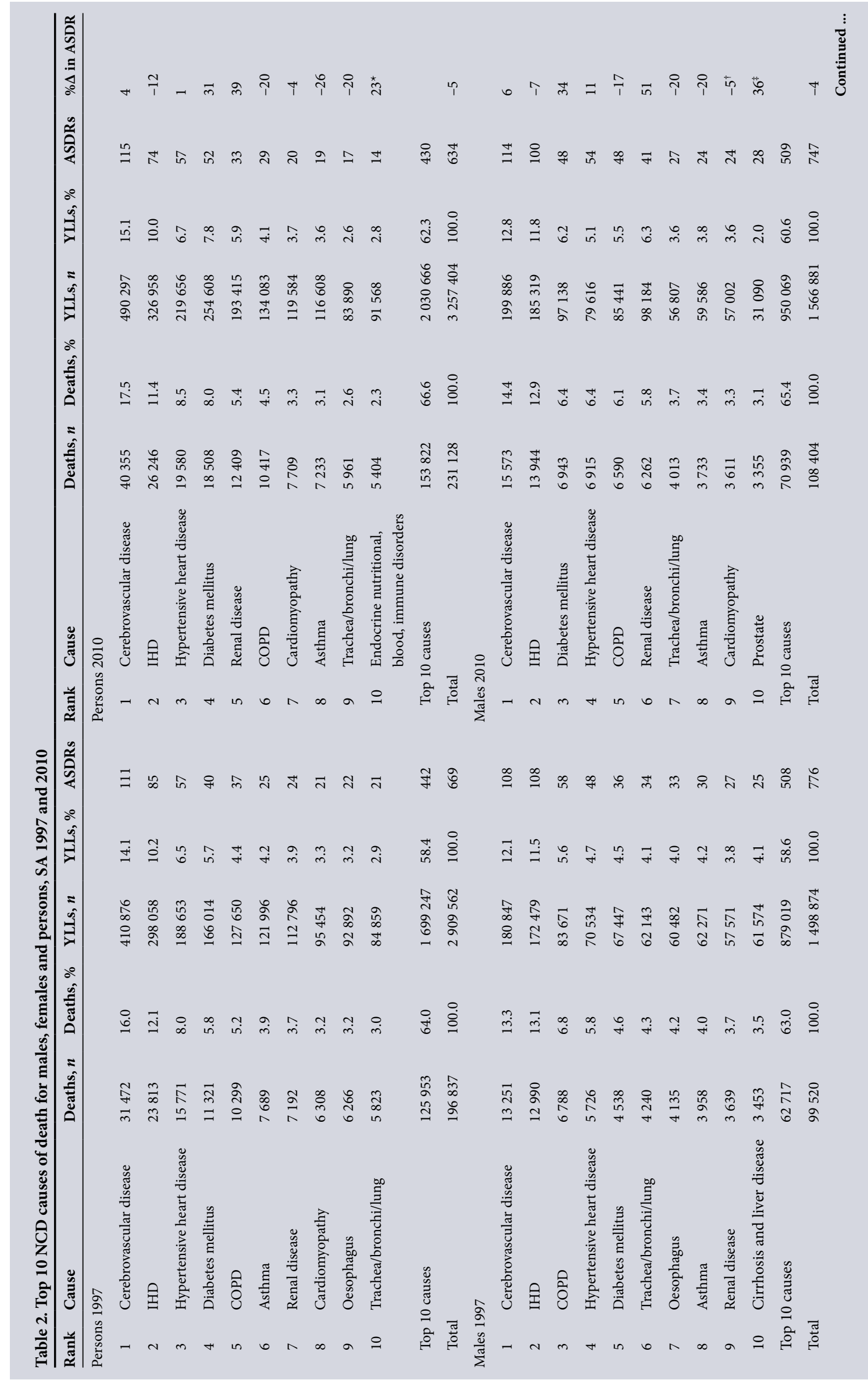




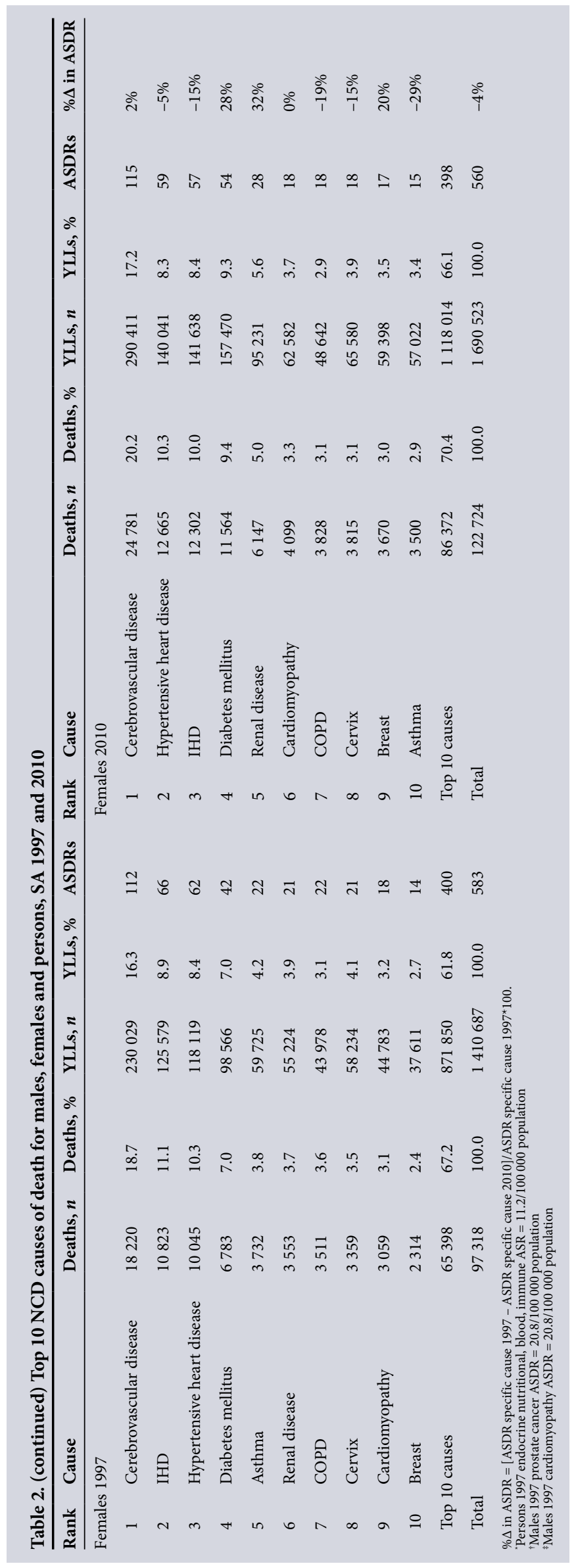

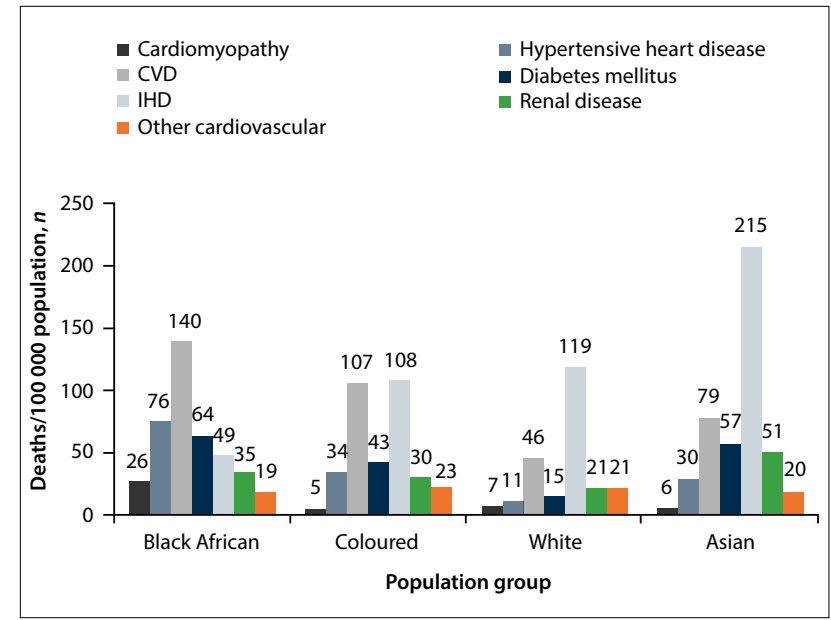

Fig. 5. ASDRs for CVDs, diabetes mellitus and renal disease by population group, SA 2010.

Population groups in different stages of the cardiovascular transition $^{[35,36]}$ are shown in Fig. 5. While Asians have distinctively high rates of IHD and renal disease, black Africans are in the midst of a CVD epidemic with relatively high mortality rates from cardiomyopathy, hypertensive heart disease, stroke and diabetes mellitus, and can be expected to transition towards IHD as living conditions and behaviours change.

\section{Cancers and chronic respiratory diseases}

Fig. 6 shows ASDRs from more common cancers. Cancer death rates for females were generally lower than for males, but the lack of national cancer incidence data makes it impossible to confirm the findings. ${ }^{[37]}$ There was a marked decline for oesophageal and lung cancer for males, while prostate cancer increased. For females oesophageal cancer decreased, with little change in lung cancer and a slight increase in breast cancer. In contrast, oesophageal cancer incidence rates for both sexes in rural populations have remained high. ${ }^{[38,39]}$ Kaposi's sarcoma deaths have not been reported, as they were reallocated to HIV/AIDS because of the strong association of this tumour with AIDS. While there has been an increase in the number of deaths due to Kaposi's sarcoma, it ranked 9th and 10th among cancers for males and females, respectively, in the raw data in recent years.

The overall mortality rate from cancers in 2010 was 114/100 000 (using the International Agency for Research on Cancer standard population as denominator, the rate was $100 / 100$ 000). However, cancer death rates differed by population group. In 2010, the cancer death rate for coloureds was 1.8 times higher than that for black Africans (Fig. 7), arising from high lung and prostate cancer rates for coloureds (Fig. 8, B and D) and low rates for black Africans for most cancers apart from oesophageal and cervical cancer (Fig. 7). There was a marked population group difference in cancers of the alimentary canal (Fig. 8, C).

Fig. 9 shows trends in death rates from chronic respiratory diseases. Males had a high mortality from COPD (about 60/100 000 population) during the early period, dropping to $48 / 100000$ population in 2010 . The rates were more than double those for females. In contrast, asthma mortality was only slightly higher for males and also declined. Fig. 10 shows that both level of mortality and the gender difference were lowest in whites.

\section{Discussion}

Over the past 14 years, NCDs have continued to be a major cause of mortality in SA, despite the country's profound AIDS epidemic. 


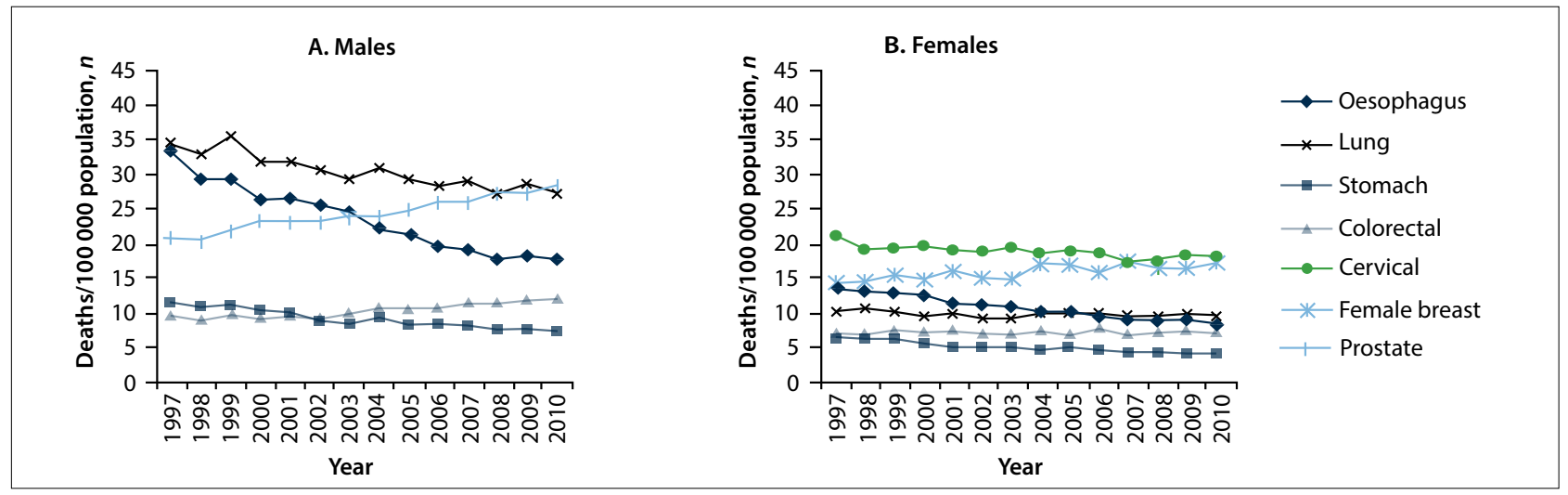

Fig. 6. ASDRs for cancers for males (A) and females (B), SA 1997 - 2010.

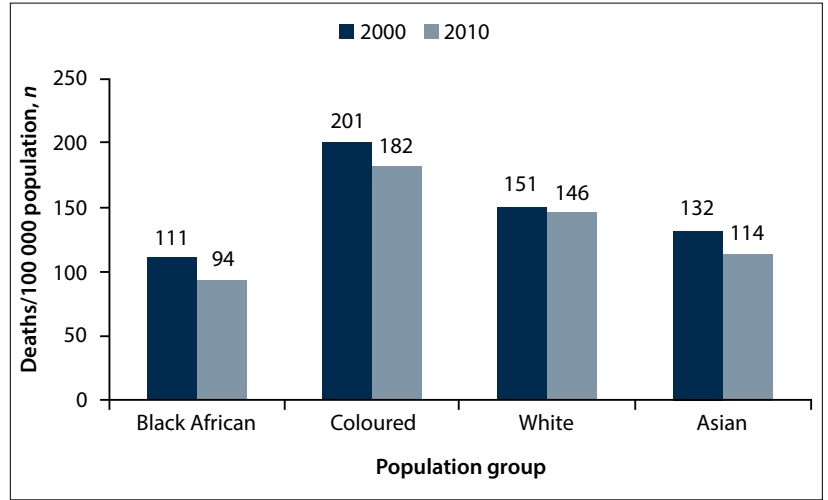

Fig. 7. ASDRs for malignant neoplasms by population group, SA 2000 and 2010.

NCDs accounted for $39 \%$ of deaths in 2010 and for considerable premature mortality. CVDs were the major NCDs, and by 2010 stroke had become the second leading cause of death after HIV/AIDS. Of the approximately 230000 South Africans who died from NCDs in $2010,36 \%$ had not reached the average life expectancy of 60 years. This study shows that there has been a steady increase in deaths due to NCDs, driven by population growth and a shift in the age structure towards older ages. However, ASDRs for NCDs declined by $0.4 \%$ per annum over this period, short of the recommended $2 \%$.

The importance of tracking cause-specific trends has been revealed, and the study shows decreasing stroke mortality from 2003 onwards, as well as declines in IHD, lung and oesophageal cancer, COPD and asthma. The early introduction of tobacco control strategies has probably contributed to these declines, along with other factors. The drop in oesophageal cancer mortality may also be related to urbanisation and dietary changes including shifts from consuming home-grown to commercial maize. ${ }^{[40]}$ In contrast, mortality from diabetes mellitus, renal disease and endocrine/nutritional and blood immune disorders has increased. This is in keeping with the increase in overweight and obesity observed in national surveys, ${ }^{[1,42]}$ urbanisation, and the observation that diabetes mellitus has increased rapidly in all age groups in urban settings. ${ }^{[43]}$ Addressing the increase in obesity is a global challenge, and in the past 30 years, no country has been able to buck the trend. ${ }^{[44]}$ Gortmarker et al. ${ }^{[45]}$ have identified priority actions that focus on policies to improve nutrition and built environments, cross-cutting actions (such as leadership, healthy public policies, and monitoring), and greater investment in prevention.

Some of these findings can be attributed to a strong gender tendency towards women being overweight and obese, and men smoking and drinking. ${ }^{[22,23]}$ Differences among population groups

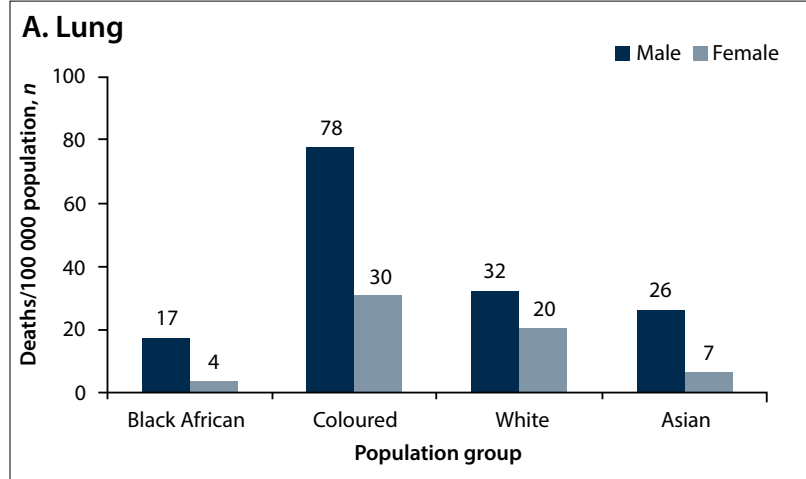

\section{B. Urogenital and reproductive organs}

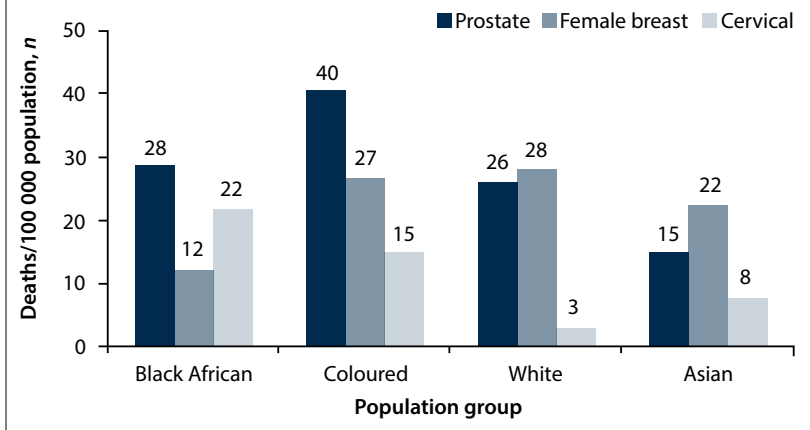

\section{Alimentary canal}

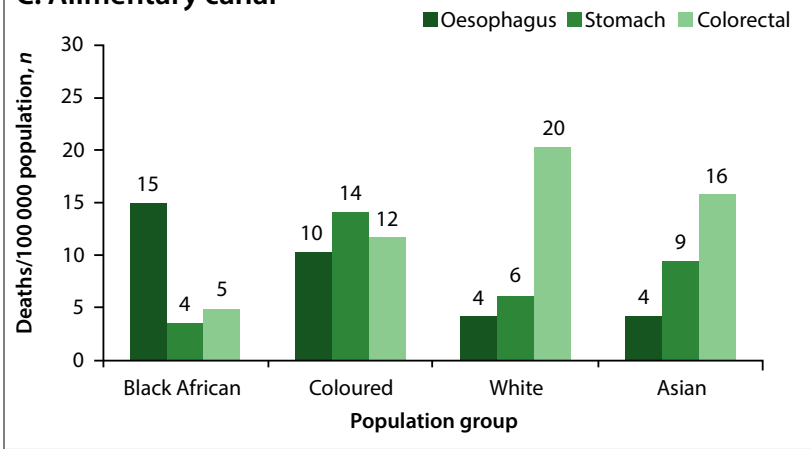

Fig. 8. ASDRs for lung cancer by sex (A), and for urogenital and reproductive organ cancers $(B)$ and cancers of the alimentary canal (C) by population group, SA 2010.

are likely to be driven by socioeconomic differentials. These inequalities are replicated in access to healthcare, screening, 


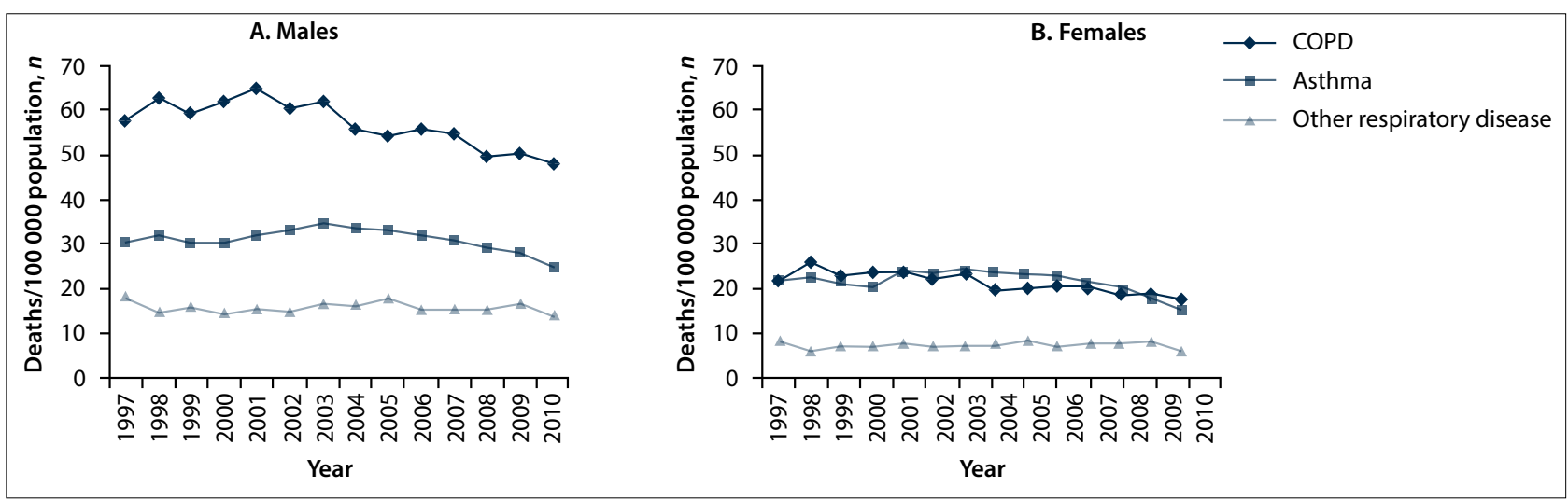

Fig. 9. ASDRs for respiratory disease for males (A) and females (B), 1997 - 2010.

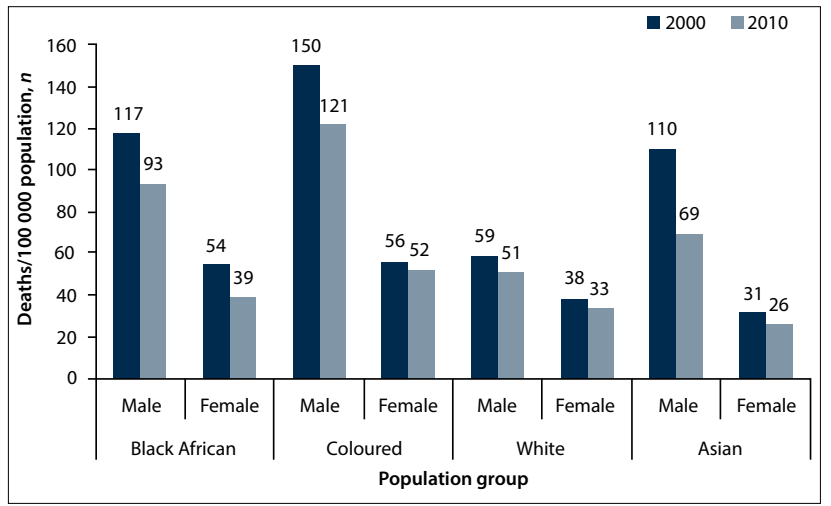

Fig. 10. ASDRs for respiratory diseases by population group and sex, 2000 and 2010.

diagnosis and treatment. ${ }^{[46]}$ Many disadvantaged people remain undiagnosed, untreated and at risk of preventable complications. Lack of health insurance results in disadvantaged people suffering higher rates of ill-health than other groups. ${ }^{[47]}$ The higher mortality rates from cardiomyopathy among black Africans compared with other groups may be attributable to underlying low socioeconomic status, ${ }^{[77,48]}$ environmental factors and historical issues (such as forced displacement, extreme poverty, and limited access to healthcare and education, employment and social services). Findings from Sliwa et al. ${ }^{[49]}$ and other studies on black Africans have established that patients affected by advanced HIV/AIDS tend to develop cardiomyopathies. ${ }^{[50,51]}$ Alcoholism, poor nutrition and low socioeconomic status have also been cited as factors contributing to cardiomyopathy.

Adopting global recommendations, SA launched a Strategic Plan for the Prevention of Non-communicable Diseases 2013-17 in September 2013. This provides an overarching framework for chronic disease prevention by promoting health and wellness at community and individual levels and strengthening primary healthcare. Building on the comprehensive tobacco control legislation, which appears to be responsible for much of the decline in NCDs, the Strategic Plan has identified key population-wide interventions to prevent and control NCDs through legislation and regulation. Salt use regulations and other nutritional policies are currently being implemented and should increase the momentum for prevention and control of NCDs. On the other hand, alcohol policy development has been slow. The substantive increases observed in mortality rates from prostate and breast cancers point to the need for more public awareness about cancers and the need for early detection and treatment services to be available.
Reliable and robust surveillance is integral to disease control and essential for planning and implementing health policy. ${ }^{[1]}$ The Strategic Plan includes time-bound targets, including the reduction of premature mortality. Improved surveillance is needed to support the Plan and should include improvements in vital registration ${ }^{[52]}$ and population-based surveys to monitor risk factors, their determinants and key intervention coverage. ${ }^{[53]}$ In addition, to monitor primary care programmes, ${ }^{[18]}$ cohort data on chronic disease patients are essential. The use of a standardised clinical summary sheet in patient folders would enable audits ${ }^{[54]}$ based on record reviews as an interim measure. This should be accompanied by a patient-held card, tracking progress on risk factors, which could help to motivate individuals to change health-related behaviours.

\section{Study limitations}

Several limitations of this study must be acknowledged. Firstly, although there have been considerable improvements, the quality of death certification is still inadequate with a relatively high proportion of ill-defined and misattributed causes. Misclassification of cardiovascular and diabetes causes has been observed, and although adjustments were made based on multiple-cause information, it is possible that a degree of error remains in our estimates. Secondly, despite regular census data being available, there is uncertainty in population estimates, which adds to uncertainty in estimated mortality rates. Thirdly, for the population group differences information was missing for about a quarter of the deaths and needed to be imputed. Nonetheless, face validity of the trends and differentials indicates that these estimates are robust, and SA clearly needs to take further steps to reach the recommended goal of a $2 \%$ reduction per annum. ${ }^{[8]}$ Tracking the emerging trends in the death rates is an essential tool to assist with monitoring and modifying the Strategic Plan.

Funding. The study was funded by the South African Medical Research Council.

Author contributions. BN and DB conceived and conceptualised the article. BN, DB, NS, JDJ and VPvW contributed to the design of the paper. WM, RL, VPvW, PG and DB contributed to the analysis, development and maintenance of the database used in the study. RED estimated the incompleteness of registration of deaths and the correction of the ill-defined causes for HIV/AIDS. All authors contributed to the editing of the text.

Acknowledgement. The authors thank the other SA National Burden of Disease team, which consists of the following members (in alphabetical order): Richard Matzopoulos, Nadine Nannan, Ian Neethling, Edward 
Nicol, Megan Prinsloo, Anastasia Rossouw and Nomfuneko Sithole. The team jointly contributed to the analysis and interpretation of the data. We thank Statistics South Africa for providing cause-of-death data and Ms Elize de Kock for administrative support on the SA National Burden of Disease Study. In addition, critical appraisal and input provided by Eric Bateman, Kirsty Bobrow, Alan Bryer, Krisela Steyn and Naomi Levitt are much appreciated.

\section{References}

1. Lozano R, Naghavi M, Foreman K, et al. Global and regional mortality from 235 causes of death for 20 age groups in 1990 and 2010: A systematic analysis for the Global Burden of Disease Study 2010 20 age groups in 1990 and 2010: A systematic analysis for the Global Bur

2. Schmidt MI, Duncan BB, e Silva GA, et al. Chronic non-communicable diseases in Brazil: Burden and Schmidt MI, Duncan BB, e Silva GA, et al. Chronic non-communicable diseases in Brazil: Bu
current challenges. Lancet 2011;377(9781):1949-1961. DOI:10.1016/s0140-6736(11)60135-9

current challenges. Lancet 2011;377(9781):1949-1961. DOI:10.1016/s0140-6736(11)60135-9
3. World Health Organization. Global Status Report on Non-communicable Diseases 2010. Geneva: WHO, 2011

WHO, 2011 .
4. Alwan A, Maclean DR. A review of non-communicable disease in low- and middle-income countries. 4. Alwan A, Maclean DR. A review of non-communicable disas
Int Health 2009;1(1):3-9. DOI:10.1016/j.inhe.2009.02.003

5. Kulik J. Reducing the Economic Burden of Non-communicable Disease in the BRICS: Lessons from Brazil. Toronto, Canada: BRICS Information Centre, University of Toronto, 2013.

6. Reddy KS. Cardiovascular diseases in the developing countries: Dimensions, determinants, dynamics and directions for public health action. Public Health Nutr 2002;5(1a):231-237. DOI:10.1079/ PHN2001298

7. Yang G, Wang Y, Zeng Y, et al. Rapid health transition in China, 1990-2010: Findings from the Global Burden of Disease Study 2010. Lancet 2013;381(9882):1987-2015. DOI:10.1016/S01406736(13)61097-1

8. Strong K, Mathers C, Leeder S, Beaglehole R. Preventing chronic diseases: How many lives can we save? Lancet 2005;366(9496):1578-1582. DOI:10.1016/s0140-6736(05)67341-2

9. Beaglehole R, Bonita R, Alleyne G, et al. United Nations high-level meeting on non-communicable disease: Addressing four questions. Lancet 2011;378(9789):449-455. DOI:10.1016/s01406736(11)60879-9

10. United Nations General Assembly. Political Declaration of the High-level Meeting of the General Assembly on the Prevention and Control of Non-communicable Diseases. New York: United Nations, 2011. http://www.un.org/ga/search/view_doc.asp?symbol=A/66/L.1 (accessed 1 April 2016)

11. World Health Organization. Draft Comprehensive Global Monitoring Framework and Targets for the Prevention and Control of Noncommunicable Diseases. Geneva: WHO, 2013.

12. Stringhini S, Sinon F, Didon J, et al. Declining stroke and myocardial infarction mortality between 1989 and 2010 in a country of the African region. Stroke 2012;43(9):2283-2288. DOI:10.1161 strokeaha.112.658468

13. Backholer K, Steven C, Nusselder WJ, et al. Age-specific trends in cardiovascular mortality rates in Australia between 1980 and 2005. Australas Epidemiol 2011;18(1):33-37.

14. Unal B, Critchley JA, Capewell S. Explaining the decline in coronary heart disease mortality in England and Wales between 1981 and 2000. Circulation 2004;109(9):1101-1107. DOI:10.1161/01. England and Wales betwe

15. Beaglehole R, Yach D. Globalisation and the prevention and control of non-communicable disease: Beaglehole R, Yach D. Globalisation and the prevention and control of non-communicable disease:
The neglected chronic diseases of adults. Lancet 2003;362(9387):903-908. DOI:10.1016/s0140The neglected char

16. Reddy KS, Yusuf S. Emerging epidemic of cardiovascular disease in developing countries. Circulation 1998;97(6):596-601. DOI:10.1161/01.CIR.97.6.59

7. Strong K, Mathers C, Bonita R. Preventing stroke: Saving lives around the world. Lancet Neurol 2007;6(2):182-187. DOI:10.1016/s1474-4422(07)70031-5

18. Maher D, Harries AD, Zachariah R, Enarson D. A global framework for action to improve the primary care response to chronic diseases: A solution to a neglected problem. BMC Public Health 2009;9(355):1-7. DOI:10.1186/1471-2458-9-355

19. Norman R, Bradshaw D, Schneider M, Groenewald P. Revised Burden of Disease Estimates for Comparative Risk Factor Assessment, South Africa, 2000: Methodological Notes. Cape Town: South African Medical Research Council, 2006

20. Mayosi BM, Flisher AJ, Lalloo UG, et al. The burden of non-communicable diseases in South Africa. Lancet 2009:374(9693):934-947. DOI:10.1016/s0140-6736(09)61087-4

21. Peer N, Bradshaw D, Laubscher R, Steyn K. Trends in adult tobacco use from two South African demographic and health surveys conducted in 1998 and 2003. S Afr Med J 2009;99(10):744-749.

2. National Department of Health. Strategic Plan for the Prevention and Control of Non-communicable Diseases 2013-17. Pretoria: National Department of Health, 2013

23. Bradshaw D, Steyn K, Levitt N, Nojilana B. Non-communicable Diseases - A Race Against Time Cape Town: South African Medical Research Council, 2011

4. Phaswana-Mafuya N, Peltzer K, Chirinda W, Musekiwa A, et al. Sociodemographic predictors of multiple non-communicable diseases risk factors among older adults in South Africa. Glob Health Action 2013;6(20680):1-8. DOI:10.3402/gha.v6i0.20680
25. Pillay-van Wyk V, Laubscher R, Msemburi W, et al. Second South African National Burden of Disease Study: Data Cleaning, Validation and South Africa NBD List. Cape Town: Burden of Disease Research Unit, South African Medical Research Council, 2014.

26. Statistics South Africa. Mortality and Causes of Death in South Africa, 2010: Findings from Death Notification. Pretoria: SSA, 2013

27. Bradshaw D, Pillay-van Wyk V, Laubscher R, et al. Cause of Death Statistics for South Africa: Challenges and Possibilities for Improvement. Cape Town: Medical Research Council, 2010.

28. Bradshaw D, Msemburi W, Dorrington R, et al. HIV/AIDS in South Africa: How many people died from the disease between 1997 and 2010? AIDS 2016;30(5):771-778. DOI:10.1097/qad.0000000000000947

29. Gold MR, Siegal JE, Russel LG. Cost Effectiveness in Health and Medicine. New York: Oxford University Press, 1996.

30. Coale AJ, Demeny P. Regional Model Life Tables and Stable Population. Princeton, NJ: Princeton University Press, 1966

31. Coale AJ, Guang G. Revised regional model life tables at very low levels of mortality. Popul Index 1989;55(4):613-643. DOI:10.2307/3644567

32. Dorrington R. Alternative South African Mid-year Estimates. Cape Town: University of Cape Town, 2013.

33. Ahmad OB, Boschi-Pinto C, Lopez AD, et al. Age Standardisation of Rates: A New WHO Standard. Geneva: World Health Organization, 2001.

34. Bradshaw D, Kielkowski D, Sitas F. New birth and death registration forms - a foundation for the future, a challenge for health workers? S Afr Med J 1998;88(8):971-974.

35. Omran AR. Epidemiological transition: A theory of epidemiology of population change. Millbank Memorial Fund Q 1971;49(4):509-538. DOI:10.2307/3349375

36. Yusuf D, Reddy S, Ounpuu S, Anand S. Global burden of cardiovascular diseases Part 1: General considerations, the epidemiologic transition, risk factors and impact of urbanisation. Circulation 2001;104:2746-2753. DOI:10.1161/hc4601.099487

37. Stefan DC, Elzawawy MA, Khaled HM, et al. Developing cancer control plans in Africa: Examples from five countries. Lancet Oncol 2013;14(4):189-195. DOI:10.1016/s1470-2045(13)70100-1

38. Somdyala NI, Bradshaw D, Gelderblom WC, et al. Cancer incidence in a rural population of South Africa, 1998-2002. Int J Cancer 2010;127(10):2420-2429. DOI:10.1002/ijc.25246

39. Somdyala NIM, Bradshaw D, Gelderblom WCA. Cancer Incidence in Selected Municipalities of the Eastern Cape Province 2003-2007. Eastern Cape Province Cancer Registry Report. Cape Town: South African Medical Research Council, 2013.

40. Somdyala NIM, Parkin MD, Sithole N, Bradshaw D. Trends in cancer incidence in rural Eastern Cape Province, South Africa, 1998-2012. Int J Cancer 2014;136(5):E470-E474. DOI:10.1002/ijc.29224

41. Department of Health, Medical Research Council, OrcMacro. South African Demographic and Health Survey, 2003. Pretoria: National Department of Health, 2007.

42. Shisana O, Labadarios D, Rehle T, et al. South African National Health and Nutrition Examination survey (SANHANES-1). Cape Town: Human Sciences Research Council, 2013.

43. Peer N, Steyn K, Lombard C, Gaziano T, Levitt N. Alarming rise in prevalence of atherogenic dyslipIdaemia in the black population of Cape Town: The Cardiovascular Risk in Black South Africans (CRIBSA) study. Eur J Prev Cardiol 2014;21(12):1549-1556. DOI:10.1177/2047487313497865

44. McPherson ME, Homer CJ. Policies to support obesity prevention for children: A focus on early childhood policies. Pediatr Clin North Am 2011;58(6):1521-1541. DOI:10.1016/j.pcl.2011.09.001

45. Gortmaker SL, Swinburn BA, Levy D, et al. Changing the future of obesity: Science, policy and action. Lancet 2011;378:838-847. DOI:10.1016/s0140-6736(11)60815-5

46. Coovadia HJ, Barron R, Sanders P, McIntyre, D. The health and health system of South Africa: Historical roots of current public health challenges. Lancet 2009;374:817-834. DOI:10.1016/s01406736(09)60951-x

47. Di Cesare M, Khang Y, Asaria P, et al. Inequalities in non-communicable disease and effective responses. Lancet 2013;381(9866):585-597. DOI:10.1016/s0140-6736(12)61851-0

48. Murray CJL, Kulkarni SC, Michaud C, et al. Eight Americas: Investigating mortality disparities across races, counties and race counties in the United States. PLoS Med 2006;3(9):e260. DOI:10.1371/journal. pmed.0030260

49. Sliwa $\mathrm{K}$, Carrington MJ, Becker A, et al. Contribution of the human immunodeficiency virus/acquired mmunodeficiency syndrome epidemic to de novo presentations of heart disease in the Heart of Soweto Study cohort. Eur Heart J 2012;33(7):866-878. DOI:10.1093/eurheartj/ehr398

50. Syed FF, Sani MU. Recent advances in HIV-associated cardiovascular diseases in Africa. Heart 2013;99(16):1146-1153. DOI:10.1136/heartjnl-2012-303177

51. Sliwa K, Damasceno A, Mayosi B. Epidemiology and etiology of cardiomyopathies in Africa. Circulation 2005;112:3577-3583. DOI:10.1161/circulationaha.105.542894

52. Joubert J, Rao C, Bradshaw D, Vos T, Lopez AD. Evaluation of national mortality statistics from civil registration in South Africa, 1997-2007. PLoS One 2013;8(5):e64592. DOI:10.1371/journal. pone.0064592

53. Steyn K, Sliwa K, Hawkan S, et al. Risk factors associated with myocardial infarction in Africa: The INTERHEART Africa study. Circulation 2005;112:3554-3561. DOI:10.1161/ CIRCULATIONAHA.105.563452

54. Govender I, Ehrlich R, van Vuuren U, et al. Clinical audit of diabetes management can improve the quality of care in a resource-limited primary care setting. Int J Qual Health Care 2012;24(6):612-618. DOI:10.1093/intqhe/mzs063

Accepted 29 February 2016. 